\title{
THE PROBLEM OF PAIN
}

\author{
By Prof. P. T. Herring, \\ UNIVERSITY OF ST. ANDREWS
}

$\mathrm{A}^{\mathrm{T}}$ $\mathrm{T}$ the Dundee meeting last September of the British Association, Section I (Physiology) paid a risit to St. Andrews, where a discussion was held in the Physiology Department of the University on the problem of pain.

The physiology of pain, interesting and important though it is, is still unsolved. Pain must be regarded as a physiological sensation of a protective character; but like many other physiological phenomena it can become pathological, and the boundary between the two is indefinable. We have no means of determining the intensity of pain, and the psychological element is often an important factor. Many different kinds of pain are described, some of which are due to the admixture of other sensations in consciousness.

For the production of sensation certain an. atomical structures are essential--receptors, afferent nerve fibres and a nerve centre or centres which translate the impulses into a conscious sensation. Not all the receptors capable of receiving pain-producing stimuli are known; but the more highly specialized nerve endings can be dismissed, for modern work has shown that they are adapted to specific stimuli only. The cornea of the eye provides an example of a structure which is supposed to be capable of receiving no otber sensation than that of pain, and in the cornea the nerve endings are naked axis cylinder terminations intimately associated with the epithelial cells which cover it. The receptors in the epidermis of the skin are believed to be of the same nature, but lying more deeply placed in the living epithelium. In the connective tissues of the true skin there are also many endings of the same kind. The skin is the protective covering of the body, and any form of stimulus which injures it is an adequate one for the production of pain.

There is a pattern of so-called pain spots in the epidermis, and by the use of a finely pointed needle it may be shown that the skin varies in the amount of pain produced by a strictly localized injury. It is not known how the nerve terminations are stimulated to discharge nerve impulses. Nerve fibres are relatively resistant to mechanical stimulation, and it is not improbable that it is the living epithelial cells which respond to injury with the production of some chemical substance which provides the adequate stimulus. The persistence of the sensation of pain after injury favours the view that a chemical agent is the exciting factor.
There is even less satisfactory evidence as to the nature of the afferent fibres which convey the impulses to the central nervous system. There are at least two possibilities. According to Müller's law of the specific irritability of nerve, there should be special fibres for the conveyance of the impulses that give rise to pain. Some observers have claimed the existence of special pain fibres. Ranson states that they are small in diameter and non-medullated. They may belong to Erlanger and Gasser's $C$ group; but these have a slow conduction rate, and, as Adrian points out, it is scarcely likely that pain-a danger signal-is dependent solely upon slowly conducting fibres. It is more probable that fibres of this description are concerned with the conveyance of pain from the viscera, but not from the outer covering of the body where the more rapid the response the better the protection afforded. The other possibility is that pain-producing nerve impulses are carried by nerve fibres which are normally concerned in the production of other effects, and that a more rapid scries of impulses, or a greater mass effect, floods the central nervous system and over. flows into tracts which convey pain-producing nerve impulses from more sensitive areas. The work of Adrian and others is on the whole opposed to this theory, and the trend of physiological opinion is at present in favour of the existence of specific pain fibres.

In the production of visceral pain, the utilization of nerve fibres ordinarily concerned in reflex action unaccompanied by conscious sensation is perhaps more likely, for it seems unreasonable to postulate the existence of special receptors and nerve fibres in organs which for many generations of individuals are never called into use.

However conveyed, all pain impulses appear to enter the central nervous system in Hughlings Jackson's lower level. In man a second neurone arises in the grey matter of the same side, decussates and runs upwards in the antero-lateral columns. Cases of syringomyelia support the view that in man there are special fibres in the spinal cord associated with the conduction of pain impulses. The fibres must make numerous con. nexions, for severe pain excites reflexes involving cardiac, respiratory and other vital physiological processes.

Afferent nuclei in the optic thalamus appear to be the basal receiving centres, and these in turn 
transmit certain of the impulses to the grey matter of the cortex. There is reason to believe that impulses reaching the optic thalamus give rise to pain, but that the sensation produced there differs in some respects from that perceired by the cortex cerebri, the pain being more diffuse, less well localized and of a peculiar character. Pain felt by the thalamus has some of the characteristics of protopathic sensibility. Head's classification of body sensation into protopathic and epicritic has been much debated. There is no doubt the distinction exists; but its exact significance remains to be determined.

The physiology of pain in structures that lie deeper than the protective covering of the body presents further problems. Many tissues and organs of the body are capable of pain, but the adequate stimulus is often a specific one, and the injuries which produce pain in the skin or parietes fail to produce any sensation whaterer in many of the viscera. Muscle, whether skeletal, cardiac or visceral, can be cut, burnt or otherwise injured without the production of sensation. Yet pain, and pain of a very severe character, can be experienced by muscle. The adequate stimulus is now believed to be tension, and particularly tension in the absence of an efficient circulation. Sir Thomas Lewis, from experimental evidence, believes that muscle under these conditions liberates some metabolic substance which diffuses rapidly and affects the sensory nerve terminations outside the actual muscle fibres. The nature of the pain-producing substance, factor $P$, is unknown.

The capability of experience of pain by the viscera may to some extent depend upon the presence in or around them of connective tissue sheaths. Peritoneal, pleural and other membraneous coverings carry their own nerve supplies, and these may be important factors in the reception and localization of pain. Pain from the viscera is commonly referred, not to the organ in question, but to some area of the body surface endowed with higher sensibility, and is then known as 'referred' pain. Prof. Waterston suggests that pain of this nature should be called 'heterotopic' to distinguish it from 'homoiotopic', or pain referred to its actual site of origin.

Ross was one of the first to attempt an explana. tion of visceral pain. He described two types, referred pain and true visceral or splanchnic pain. Mackenzie, impressed by his own observations on the insensitivity of the viscera, elaborated Ross's theory of the radiation of pain from the viscera to the parietes through an irritable focus in the spinal cord, but denied the existence of true visceral pain. Mackenzie believed that pain associated with a diseased viscus is never felt in that organ, but is always referred to an area of higher sensibility in the body wall. The pain may be extremely severe, and accompanied by reflexes, local and general. The local manifestations are of great value to the clinician in that they give him information as to the site and extent of the disturbance. The details of the work of Ross and Mackenzie have been much debated. Prof. Mforley, who spoke at the meeting, considers that Mackenzie failed to appreciate the difference between referred pain from the parietal peritoneum and that from an intraperitoneal viscus. Morley believes that referred pain arises from the irritation of nerves sensitive to those stimuli which produce pain when applied to the surface of the body. Ho considers that pain from the urinary system, which is retroperitoneal, harmonizes with Mackenzie's view, though gastro-intestinal pain does not. The difficulty arises because of the complication introduced by the presence to a varying extent in the abdominal viscera of peritoneum and mesentery, structures carrying their own nerve supplies, and differing in their sensitivity.

Mackenzie believed that excessive contraction of muscle is the cause of pain in whatever viscus it is found. Colic and the pain of hunger may be cited as examples. Payne and Poulton, in a series of careful experiments, came to the conclusion that visceral pain from muscle is caused, not by its contraction directly, but by tension, and that the stimulus is a stretching and deformity of pain endings in the wall of the stretched viscus. The frequent association of pain with contraction is explainable on the assumption that excessive tension is put upon the tissues with which the contracted fibres are in continuity.

Headache presents another interesting problem. Apart from local conditions, such as neuralgia affecting the scalp, and vascular spasm in the tegumentary covering, headache is often a referred pain, and its source some part of the alimentary tract. The afferent nerves are those of the visceral fibres of the vagus, and the pain is referred to areas supplied by the trigeminal nerve. Some disturbance in the abdomen gives rise to pain which is felt as a headache. When the pain is of intracranial origin, its cause is now commonly ascribed to vascular changes in the pia-arachnoid membrane of the brain. The intravenous injection of histamine sets up severe headache. Histamine is a powerful rasodilator, and congestion of the blood vessels induced by its action is thought to be the cause of the pain. Withdrawal of cerebrospinal fluid by lumbar puncture has much the same effect by decreasing the intracranial pressure. The receptors are apparently in the pia-arachnoid membrane, but may also be present in the choroid plexuses. 
Even more interesting than pain is the problem of its relief. Intractable pain is fortunately rare but does occur in some diseases. Opium and its derivatives, though of great value, are not altogether satisfactory, especially when the pain is lasting; and they have other drawbacks. Section of afferent nerves, extirpation of ganglia and other destructive procedures, have been used in intractable pain. All such methods are attempts to prevent the passage of pain-producing impulses by the afferent nerves to the central nervous system. Mr. Todd described a method of alleviation by the intrathecal injection of alcohol. This paralyses the afferent fibres in the spinal canal, and has proved valuable in cases suffering from pain in the pelvis and lower limbs. There is still room for some drug which will possess the ideal properties.

\section{METAMORPHISM AND IGNEOUS ACTION* \\ By Prof. H. H. READ, F.R.S., \\ Imperial College of Science and Technology, London}

\begin{abstract}
$A^{1}$ PART from the question of the time-continuity of the progressive series represented by, say, the Barrovian zones, there is the chemical continuity to be considered. How far do the zones of Barrow represent an isochemical series of pelitic rocks? The degree to which such processes as metamorphic differentiation and diffusion have operated obviously affects the compositions of members of the series at any stage. Such possible departures from the isochemical series arise through processes inherent in the rock. There is, however, another aspect of this topic which, though usually ignored in Great Britain, must in my opinion be carefully considered. The possibility of the introduction of material of so-called magmatic origin is one that certainly cannot be dismissed in the higher grades, and one that might apply eren to the lower grades of regional metamorphism. It will be convenient for the development of my argument, however, if we transfer ourselves to the domain of ultrametamorphism, and I discuss the reality of granitization, for, if granitization is real, certain consequences seem to follow.
\end{abstract}

In a paper which has appeared during the writing of this address, granitization is defined by Nalcolm MacGregor and Gilbert Wilson as "the process by which solid rocks are converted to rocks of granitic character". It includes all such operations as palingenesis, syntexis, transfusion, permeation, metasomatism, migmatization, injection, assimilation, contamination, and the like. These authors conclude that exchanges take place between the country-rocks and their pore-fluids-whether these are entirely indigenous or reinforced by accessions from magmatic sources-and that these exchanges are selective so that there is a conrergence, both chemical and mineralogical, of rocks originally different. They consider two processes to be concerned in granitization; first,

*Continued from page 731. a metasomatism under the influence of "permeat. ing highly energized fluids-cmanations-ahead of advancing magma", and second, a mechanical penetration by magma. I consider that no reasonable objection can be raised to these conclusions, notwithstanding the uncompromising attitude of Rosenbusch and others.

The question of room in migmatization is one that has caused difficulties to many observers. This room-question was answered by Hugh Miller fifty years ago, and has been answered many times since. Replacement is the essential process in the formation of the migmatites. It is unfortunate that the term injection-complex, used in Great Britain, emphasizes injection, since permeation, imbibition and metasomatism are more widespread phenomena. As I have pointed out elsewhere, the formation of banded gneisses and litpar-lit complexes is best explained by a process of replacement to different degrees along layers of different permeabilities. The many examples of the tracing of the regional country-rock structure through granitic masses, the existence of thin plane screens of country-rock in them, the great extension of minute lits of quartzo-felspathic material in migmatites, and the detailed heterogeneity of many granites are all readily explicable by a replacement origin for these rocks.

Replacement in sedimentary rocks will be controlled by the original structures of such rocks. Permeation by the emanations or ichors will take place preferentially along certain layers depending upon both the chemical and physical nature of these layers. Original platy minerals lying in the bedding planes will become enlarged if they suit the new chemical environment, and new-formed minerals will grow so that their direction of greatest crystallization-velocity agrees with the old planes of weakness. The original sedimentary structure may thus become preserved until a high 